\title{
The Use of Artesunate Combination Therapy (Acts) and Long- Lasting Insecticidal Net (LLIN) in Low Endemic Area to Achieve Malaria Elimination in Indonesia
}

\author{
Rita Kusriastuti ${ }^{1 *}$, Satoto Tri Baskoro² ${ }^{2}$ Iwan Dwiprahasto ${ }^{3}$ and Hari Kusnanto ${ }^{4}$ \\ ${ }^{1}$ University of Gajahmada Yogyakarta and Ministry of Health Indonesia, Indonesia \\ ${ }^{2}$ Vector and Parasitology Department, University of Gajah mada, Yogyakarta, Indonesia \\ ${ }^{3}$ Vice Rector University of Gajahmada, Yogyakarta, Indonesia \\ ${ }^{4}$ Head of Environmental and ecology study and Promoter of doctorate degree, Public Health Faculty, University of Gajahmada Yogyakarta, Indonesia
}

*Corresponding author: Rita Kusriastuti, University of Gajahmada Yogyakarta and Ministry of Health Indonesia, Tel: +62 214 287758 ; E-mail: ritakus@yahoo.com

Received date: April 03, 2014; Accepted date: May 20, 2014; Published date: May 27, 2014

Copyright: $\odot 2014$ Rita K, et al. This is an open-access article distributed under the terms of the Creative Commons Attribution License, which permits unrestricted use, distribution, and reproduction in any medium, provided the original author and source are credited.

\begin{abstract}
Malaria elimination in Indonesia was launched officially as a national program in 2008 following a commitment during the 60th World Health Assembly in 2007. Indonesia's three major malaria elimination goals include: 1) An annual parasite incidence (API) below 1 per 1000 population 2) Absence of indigenous cases 3) Active surveillance. Another key component of Indonesia's elimination strategy includes the use of artesunate combination therapy (ACT) in place of chloroquine, because of evidence for widespread resistance.

Objective: The objective of this study is to assess the impact of a new policy in malaria treatment using ACT in place of chloroquine together with long-lasting insecticidal net (LLINs) in order to achieve malaria elimination in two low malaria endemic areas (where the API are ranging from $1-5$ per 1000 population): in Sabang city in Aceh Province, located in the western part of Indonesia and in the Jembrana district, in Bali province located in the eastern part of Indonesia.
\end{abstract}

Method: Epidemiological data were collected from health centers and district health offices from 2008 to 2011 using a standardized reporting form. Both qualitative and quantitative data were collected. In-depth interviews with the authorities, health workers and other key informants such as village malaria volunteers, combined with direct observations were conducted in the two study areas.

Result: In combination with LLINs and ACT beginning in 2008 there was decrease in the incidence of malaria in Sabang city from $3.7 / 1000$ population in 2008 to $0.08 / 1000$ population in the 2011 , a decrease of almost 50 fold. No indigenous cases were found and a program of active surveillance is in place including surveillance immigrants to and from villages by local volunteers. Similarly in Jembrana district, since the widespread use of ACT and LLINs distribution there was a sharp fall in the incidence from $0.94 / 1000$ population in 2008 to $0.05 / 1000$ population in 2011, decrease of almost 20 fold over 3 years. An absence of indigenous cases reported and an active surveillance is in place by local volunteers.

Conclusion: The combination of treatment activity used ACT and prevention used LLINs can reduce malaria even in low endemic. Active surveillance activity was required to ensure the absence of indigenous cases from the area. The model of malaria activities in Sabang city and Jembrana district can be implemented in all low malaria endemic areas in Indonesia in order to obtain the national goal of malaria elimination.

Keywords: Malaria elimination; RDT; ACT; LLIN

\section{Introduction}

Malaria remains as public health problem in Indonesia mostly in eastern part such as Maluku and Papua. Overall Indonesia has 424 endemic malaria districts out of a total of 576 districts $(73,6 \%)$ and it is estimated that $45 \%$ total Indonesian population are at risk of malaria [1-3]. From a household survey conducted in 2001 the total number of cases annually was estimated to reach 15 million cases down to 1.8 million cases recorded in 2010 [4].
There are 24 recorded species of Anopheles sp. who act as malaria vector [5] and all four major parasite species were found with majority is caused by either Plasmodium falciparum or $P$. vivax, while $P$. malariae and $P$. ovale are restricted to the only the Eastern part of Indonesia [6]. Chloroquine resistance to $P$. falciparum emerged in 1973 in Indonesia and to $P$. vivax in $1991[7,8]$.

In 2008, the Indonesian Ministry of Health announced at World Malaria Day a commitment to malaria elimination. The cornerstone of its elimination efforts including widespread use of artemisinine-based combination therapy (ACT) as a first line drug, with either artesunate amodiaquine (2008-2010) or dehidro arteminisin piperaquine (DHP) from 2010 to the present, together with LLINs $[9,10]$. This study 
Citation: $\quad$ Rita K, Satoto TB, Iwan D, Hari K (2014) The Use of Artesunate Combination Therapy (Acts) and Long- Lasting Insecticidal Net (LLIN) in Low Endemic Area to Achieve Malaria Elimination in Indonesia. Malar Chemoth Cont 3: 118. doi:10.4172/2090-2778.1000118

Page 2 of 7

evaluated progress in malaria elimination in two study areas, Sabang city in Aceh Province and Jembrana district in Bali Province.

The objectives of the study is to assess the impact of new policy in malaria treatment using ACT and to asses other malaria control activities to reach malaria elimination, in Sabang city and Jembrana District, Indonesia.

The method used is a retrospective case study employed a variety of qualitative approaches including historical record review, key informant interviews and extraction of policy documents that support malaria elimination. The quantitative approach used by retrieving records on malaria program intervention and epidemiological indicators.

\section{Sample selection}

The study was conducted in the two low endemic areas (the API is ranging from 1-5/1000 population) from base line data on 2008 . Sabang city located in Weh Island is part of Aceh province in western part of Indonesia and Jembrana district, part of Bali province in eastern part of Indonesia (Figure 1). The two areas were chosen to represent a range of malaria eco-epidemiological, environment and program activities toward malaria elimination. Data collected from year 2008-2011.

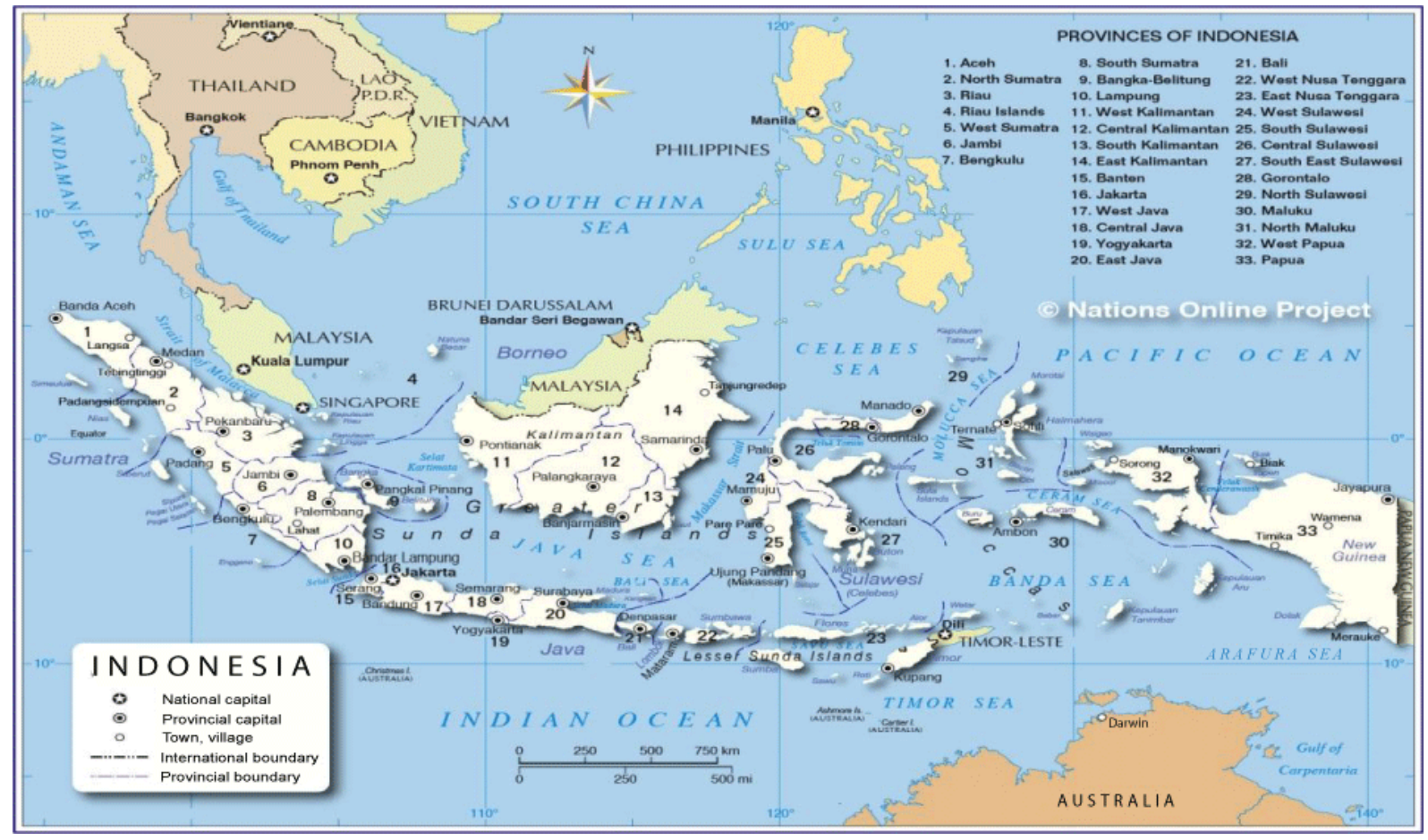

Figure 1: Map of Indonesia and the 2 study sites: Sabang city in Aceh Province and Jembrana District in Bali Province.

\section{Data collection}

From February to July 2012, a team of researchers from the Ministry of Health went to Sabang city and Jembrana district to conduct key informant interviews and retrieve records on program activities. Interview and data collection began at provincial level, district/city and health centers staff regarding case finding, case confirmation, treatment, and LLIN distribution and surveillance activities from year 2008 to 2011. The interview also conducted to village malaria volunteer in each study site. Interviews used a semi structured questionnaire asking about the history of the malaria program, epidemiological situation, organizational structure and activities of health offices/malaria officer. Interviews were tape recorded for transcription. Key indicators for malaria epidemiology, intervention activities and population data were collated from monthly report from health center and district health office as well as from annual report of district health office. All available data were accessed, cross checked and triangulated when possible since there was discrepancy. A total of 40 key informants were interviewed, including related stake holder such as Major, Head of District Health office, malaria program manager, malaria field staff at health center, village malaria volunteer and member community.

\section{Data analysis}

The data were organized and analyzed regarding epidemiological indicator of case confirmation, treatment using ACT and LLIN distribution in relation to three major malaria elimination goals set up by WHO: 1). An annual parasite incidence (API) below 1 per 1000 population 2) Absence of indigenous cases 3) Active surveillance activities. 
Citation: $\quad$ Rita K, Satoto TB, Iwan D, Hari K (2014) The Use of Artesunate Combination Therapy (Acts) and Long- Lasting Insecticidal Net (LLIN)

Page 3 of 7

\section{Result of the Study}

\section{Characteristic of the study population}

The area of Sabang city is $83 \mathrm{~km}^{2}$ divided into 2 sub district Sukakarya and Sukajaya consisting of 18 villages. Total population based on 2011 census data is 37.723 people with composition 15.600 men and 15.053 women. The age composition were $<1$ year: $12,33 \%$, 1-4 years: 10,38\%, $4-15$ years: 8,4\% 15-45years: $49,29 \%$ and above 45 years were $19,61 \%$. The land consists of soil in the hilly, rock stone/ atoll in the coastal and surrounding by the sea. There is a lake name Danau Aneuk Laot. Sabang city have 1 district health office, 1 hospital, 2 health centre and 78 village malaria volunteers. Many of the adult population are working out of Sabang city, working in malaria endemic areas in Aceh province.

The area of Jembrana district is $841.80 \mathrm{~km}^{2}$, divided into $5 \mathrm{sub}$ districts with total population (2010) is 304.956 which is male population of $152.525(50,01 \%)$ and female $152.431(49,98 \%)$. The age composition were $<1$ year: 8,51\%, $1-4$ years: $9,35 \%, 4-15$ years: $9,14 \%$, $15-45$ years: $47,07 \%$ and above 45 years were $25,93 \%$. Southern part of Jembrana is an Indian Ocean and west part is the Bali strait, so it has long coastal areas which are prone to breeding places of the anopheles. Jembrana distrcit have 1 district health office, 1 hospital, 6 health centers with medical doctor's average 4 person per H.C, 1 malaria officer, 1 microscopist and midwives and nurses. In hospital there are $44 \mathrm{MD}$ and 120 paramedics and have 78 village malaria volunteers. Two percent of the community work as fisherman that sail far across the ocean to the Maluku and Papua where is still high endemic of malaria.

\section{Malaria control program}

\section{Epidemiological situation in Sabang and Jembrana}

The National Malaria Control Program goal was shifted toward malaria elimination in 2008 followed by shifted of treatment strategy from monotherapy to combination therapy used ACT [21]. This strategy was adopted and followed by all the malaria endemic areas throughout Indonesia. Both in Sabang city and Jembrana district, the health services began to use ACT to all positive malaria cases in 2008 . They also conducted strengthening the early detection and diagnosis activity by training the microscopist and also LLIN distribution From analyzing the data in Sabang city, the API in 2008 was 3.7/1000 population and decreased to $2.6 / 1000$ population in 2009 (1.42 times), and to $0.9 / 1000$ population in 2010 , the API already below $1 / 1000$ population, continued to decrease to $0.08 / 1000$ population in 2011 (Figure 2). In Jembrana district, in 2008 the API was 0,94/1000 population and drop to $0.04 / 1000$ population in $2009,18.8$ times, after 2009 the API relatively stable at around $0.05 / 1000$ population (Figure $3)$.

\section{Case finding and treatment activity}

From table 1 case finding and ACT treatment in Sabang city we analyzed that since $2008,100 \%$ suspected malaria were examined, $96 \%$ examined by microscope, only few $4 \%$ tested by RDT and found $12 \%$ were positive and began to treat with ACT. We observed that year by year decreasing the number of positive cases. In 2011 only found 3 cases, the positivity rate is $0,02 \%$. The API decreased from $3,7 / 1000$ population in 2008 to $0,08 / 1000$ population in 2011 , decreased $97,8 \%$ or 46,25 times.

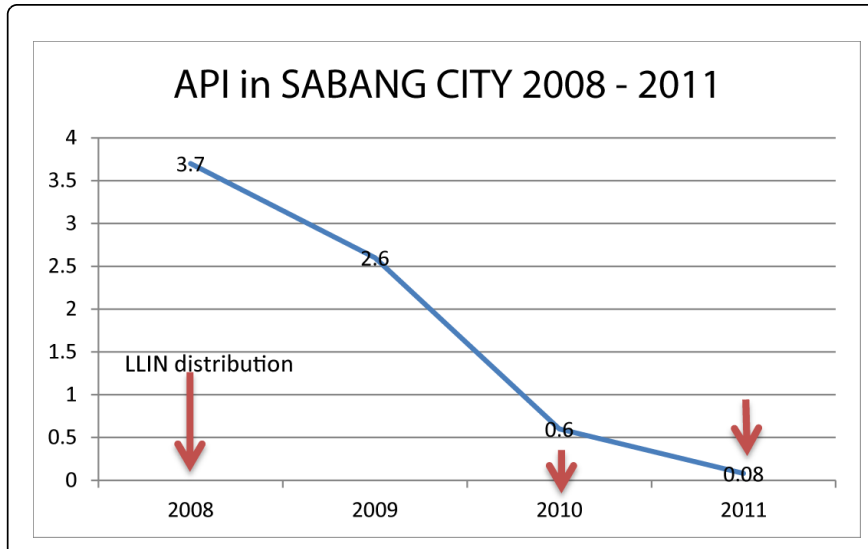

Figure 2: API trend in Sabang city, Aceh Province.

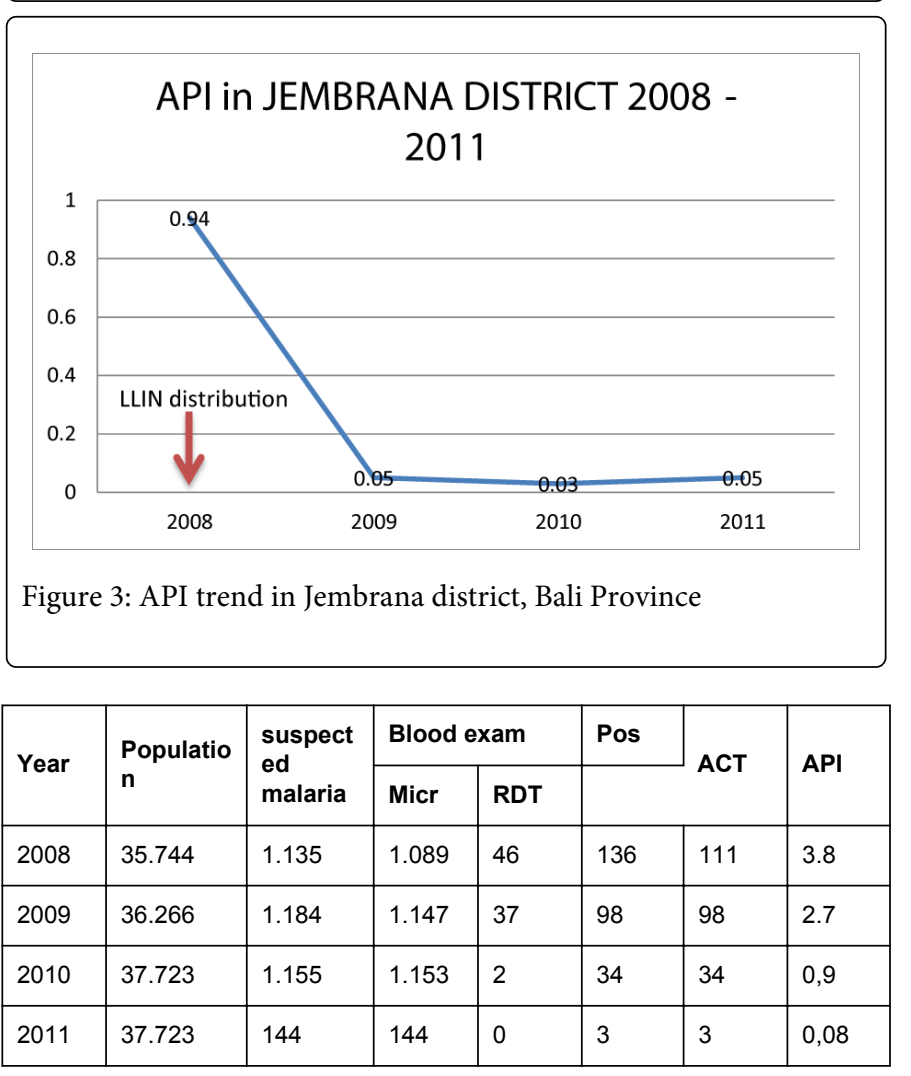

Table 1: Case finding and ACT treatment activity in the Health Centre, 2008-2011, in Sabang City.

In Jembrana district never used RDT for confirmation of suspected malaria, always used microscopic examination. From the interviewed we've got the information that in 2007 and 2008 malaria cases was increased due to weakened of the surveillance activity, where there were an imported cases and neglected. But since 2008 the surveillance activity was strengthened, used of ACT for treatement as well as strengthened the malaria village cadres. The LLIN distribution only in 2008. As a result in the year 2009 the cases was drop sharly, only found 12 cases with API 0,05/1000 population (Table 2). 


\begin{tabular}{|c|c|c|c|c|c|c|c|}
\hline \multirow{2}{*}{ Year } & \multirow{2}{*}{$\begin{array}{l}\text { Populatio } \\
\text { n }\end{array}$} & \multirow{2}{*}{$\begin{array}{l}\text { suspect } \\
\text { ed } \\
\text { malaria }\end{array}$} & \multicolumn{2}{|c|}{ Blood exam } & \multirow[t]{2}{*}{ Pos } & \multirow{2}{*}{ ACT } & \multirow{2}{*}{ API } \\
\hline & & & Micr & RDT & & & \\
\hline 2008 & 261.638 & 3.367 & 3.367 & 0 & 245 & 245 & 0,94 \\
\hline 2009 & 264.674 & 2.781 & 2.781 & 0 & 12 & 12 & 0,05 \\
\hline 2010 & 264.674 & 2.705 & 2.705 & 0 & 9 & 9 & 0,03 \\
\hline 2011 & 307.804 & 3.176 & 3.176 & 0 & 15 & 15 & 0,05 \\
\hline
\end{tabular}

Table 2: Case finding and ACT treatment activity in the health center, 2008-2011, in Jembrana district.

\section{LLIN distribution}

In Sabang city the nett distribution firstly after the tsunami disaster in 2005, but it was not well recorded. From the data in 2008 the net was distributed only to 7 villages with 11.160 population, LLIN coverage was 1.34 which means that all house hold have 1-2 LLIN/ house. In 2010 the LLIN was distributed to all 18 villages but the number of LLIN was decrease, it was only to $1 / 3$ of house hold compare to 2008. It was only distributed to areas which were found positive cases. The source of the net is from Global Fund. Repeated LLIN distribution was conducted in 2011, so that in Sabang city the total 18 villages got at least 1 LLIN (Table 3 ).

\begin{tabular}{|l|l|l|l|l|}
\hline \multirow{2}{*}{ Year } & \multirow{2}{*}{ Population } & No of & LLIN & LLIN/ \\
\cline { 3 - 5 } & & H.H & DISTR. & H.H \\
\hline 2008 & 11.16 & 2.12 & 3.119 & 1.34 \\
\hline 2010 & 37.531 & 7.506 & 1.105 & 0.14 \\
\hline 2011 & 27.305 & 6.492 & 5.461 & 0.84 \\
\hline
\end{tabular}

Table 3: LLIN Distrubtion in Sabang City, 2008-2011.

While in Jembrana district only 3 health centers and 12 endemic villages that received LLIN and only in year 2008, after that, no more net distribution (Table 4). Despite that, we can see that number of malaria cases in 2009 on ward was declined.

\begin{tabular}{|l|l|l|l|l|l|}
\hline \multirow{2}{*}{ No } & \multirow{2}{*}{$\begin{array}{l}\text { Health } \\
\text { center }\end{array}$} & & No of & No of LLIN & \multirow{2}{*}{ LLIN/H.H } \\
\cline { 3 - 5 } & & Population & H.H & Distributed & \\
\hline 1 & Melaya & 28.502 & 4072 & 600 & 0.15 \\
\hline 2 & Kaliakah & 38.359 & 5480 & 570 & 0.1 \\
\hline 3 & T. dangin & 1.587 & 300 & 30 & 0.1 \\
\hline
\end{tabular}

Table 4: LLIN Distribution Jembrana District in 2008.

LLIN only distributed in the areas of health centers where reported of positive malaria cases, as in 2008 there were 245 malaria cases reported. But in 2009 only reported 12 positive malaria cases.

\section{Parasite surveillance}

The health facilities conducted passive and active case detection and mostly examined by microscopy for confirmation of the malaria cases. The proportion of infections due to $P$. falciparum - $P$. vivax said to be
$\mathrm{Pf} / \mathrm{Pv}$ ratio in Sabang city was 2,4 in 2008; 3,6 in 2009; 3,25 in 2010 and 2 respectively in 2011. It means that most of the time $P$. falciparum still the dominant strain. Since the use of ACT regimen which is artesunate-amodiaquine (AS-AQ), we observed a steady decrease of P.f as well as P. v infection. In 2011 only 3 malaria imported cases were reported (2 P. falciparum and $1 P$. vivax) (Table 5).

\begin{tabular}{|l|l|l|l|l|}
\hline Year & P.f & P.v & Mix & Total \\
\hline 2008 & 87 & 36 & 13 & 136 \\
\hline 2009 & 68 & 19 & 11 & 98 \\
\hline 2010 & 26 & 8 & 0 & 34 \\
\hline 2011 & 2 & 1 & 0 & 3 \\
\hline
\end{tabular}

Table 5: Type of parasite in Sabang city, 2008 -2011.

Table 6 showed that control of malaria in Jembrana district has been succeed in controlling $P$. falciparum as well for $P$. vivax. The $P$. vivax infction was dominated, the P.f/P.v ratio is 0.5 in 2011. Although from many references said that $P$. vivax is difficult to handle because there is a hipnozoit phase, a condition where the parasite hide in the liver and and stay doormant, no activity and no sign symptom but on certain condition the parasite will active again and show the symptom $[11,12]$. Other reason is due to long treatment that took 14 days, so it depends on compliance of the patient [13].

\begin{tabular}{|l|l|l|l|l|}
\hline Year & P.f & P. v & Mix & Total \\
\hline 2008 & 4 & 241 & 0 & 245 \\
\hline 2009 & 5 & 7 & 0 & 12 \\
\hline 2010 & 2 & 6 & 1 & 9 \\
\hline 2011 & 5 & 10 & 0 & 15 \\
\hline
\end{tabular}

Table 6: Type of parasite in Jembrana district, 2008 -2011.

\section{Vector surveillance}

In Sabang city, there are many species of Anopheles, including $A$. aconitus, $A$. sundaicus, $A$. subpictus, A. flavirostris, $A$. minimus and $A$. dirus. Those mosquitos behavior are different, A. subpictus, $A$. flavirostris and $A$. aconitus are indoor biting and indoor resting while $A$. sundaicus, $A$. minimus and $A$. dirus are outdoor biting and resting [14-17]. While in Jembrana district only one type of mosquito found that is A. sundaicus [18]

\section{Active surveillance by community}

Sabang city trained 18 malaria volunteers, one person per village in the year 2008 and scaled up to recruit 78 volunteer in 2010. They trained on surveillance activities. Their task was to conduct home visit twice a month in an active or residual village and visit once a month in non-active area. They observed and recorded the local resident travel history and a fever case. If they found a fever case they report to the health center for a blood examination followed by conducting a contact survey and taking a blood smear to family members. Other task of VMV is to inspect the larval habitat and monitoring the use of LLIN. 
In Jembrana district recruited and trained $25 \mathrm{VMV}$ in 2009, their role and function are to conduct migration surveillance by monitoring the movement of the local resident. In collaboration with Head of villages and private doctors/clinics, they conducted a fever surveillance, if there is a fever person, will take a blood smear; to supervise the ingestion of the drug by the patient and to monitor the environment by checking the algae in lagoon and working together with head of community and community itself to clean the environment.

\section{Qualitative data}

From in-depth interviewed and focus group discussion with stake holder and VMV, we've got information as follows:

\section{Major of Sabang Municipality:}

"After tsunami there were many students from universities and research organization conducted a research on malaria, it help a lot to the malaria program and to our area to achieve Sabang free of Malaria”

He also stated: "We committed and support the health sector so we welcome any donors to help. We also works collaboratively with Indonesian Medical Association, Medical Faculty, UNICEF, Global Fund"

\section{Head of Health Office Sabang stated:}

"We got chance to attend the international meeting (APMEN-Asia Pacific Malaria Elimination Network) in Colombo, we've got full support from our Major, it is increased our motivation to work harder to achieve malaria elimination"

\section{Head of Jembrana District Health office stated}

"There are one or two falciparum malaria appear in this area because of the Jembrana citizen who transmigrate to other islands and after they succeed they came back to their village, but bringing malaria parasite with them"

\section{He also stated:}

"We had got support funding from our local government as well as support funding from Provincial health office for malaria program mostly are for VMV incentive"

\section{Health office program manager of Jembrana district stated that:}

"Last outbreak was in 2002 in due to the breeding places just in the back yard of people houses, where is a long the coastal there were neglected shrimp or fish fishery there are also many lagoon which water are trapped there".

\section{Village Malaria Volunteers statement are:}

"Our task is conduct an active case detection (ACD) through working together with private medical doctor by asking if there is a fever patient which just going out from our village"

"If we got the information of the fever case, we come straight to the patient house to monitor the environment as well as 10 of neighboring houses"

"We took his/her blood sample and made thich and thin smear and send to the laboratory in health center. If the result is positive, we also observe directly to the patient during they taking a drug, every day we will come to the house of the patient".
"We also monitored an incoming people from transmigration areas mostly from Sulawesi which came for religious festive. We also monitored fisherman. We work in coordination with the chief of local neighborhood"

The village malaria volunteers are getting monthly incentives from local government. In Jembrana district there is a path carrier for VMV after their serving for 5 years they have a chance to be recruited as government employee.

\section{Discussion}

The government of Indonesia has committed toward malaria elimination which is in line with the global public health agenda that was launched during The 60th World Health Assembly in 2007 by released a National Malaria Elimination decree in 2008. The effort to achieve malaria elimination goal will be conducted in phases, by year and by islands wise begin from 2010 until 2030. The first ever district announced and given the certificate of malaria elimination from the Ministry of Health, is Thousand island district in Jakarta province during the commemoration of World Malaria day in April 2013 [19]. Immediately after the National elimination program was launched the malaria control program made re orientation of its malaria control program and change the malaria treatment policy which is stop using monotherapy, chloroquine and began to use Artesunate Combination Therapy (ACT) $[4,10]$. It is a must to confirm the suspected cases either by microscope examination or by RDT. Current malaria treatment policy is called radical treatment which includes ACT and primaquine (PQ). The regimen of Artesunate Amodiaquine was chosen as first line drug, with the dosage of artesunate is $4 \mathrm{mg} / \mathrm{Kg}$ body weight per day, amodiaquine is $10 \mathrm{mg} / \mathrm{KgBW}$ per day. For treat $\mathrm{P}$ falciparum ACT is given for 3 days plus 1 day primaquine with dosage $0,75 \mathrm{mg} / \mathrm{Kg} \mathrm{BW}$ given only at day one [4]. While for treatment of $P$. vivax the ACT was given plus primaquine with the dosage of primaquine is $0,25 \mathrm{mg} / \mathrm{Kg} \mathrm{BW}$ or 1 tablet per day for 14 days.[4]. No wonder if the rejection to take a full course of drug was high and the compliance was low. The severe adverse effect of the AS- AQ was reported from many malaria endemic parts in Indonesia. By that evidence based information the ministry of health of Indonesia considered to revise and make a fixed dose combination AS-AQ tablets with monitoring of good manufacturing product, it reduces the number of the drugs ingested as well as the adverse effect [20 ]. Due to adverse effect of AS-AQ such as severe headache, nausea, vomiting, after two years using AS-AQ, in $2010 \mathrm{MoH}$ by the recommendation from expert group on malaria, changed the regimen of ACT to use Dehidro Artemisinin Piperaquine (DHP). Both drug AS-AQ and DHP are provided for free by the government.

The Sabang situation after tsunami hit the area in 2005, the ACT already used in that area brought and introduced by international agencies but not recorded well, yet chloroquine still used for malaria treatment in many health facilities [21]. Followed National Policy for treatment in using ACT in 2008 as well a good data recording and reporting as well as mapping and active surveillance activities by VMV, it was observed a steady decreasing of malaria cases, either $P$. falciparum and or $P$. vivax. Although from many references said that $P$. vivax is difficult to handle because there is a hipnozoit, a condition where $P$. vivax is hiding in the liver in dormant stage, looks like no parasite activity, either no sign nor symptom but on certain condition the parasite will activate again and show the symptom [11-13] With hipnozoit the possibility for relapse to occur is higher $[11,12]$. The drug policy of radical treatment which combine ACT plus PQ can 
Page 6 of 7

tackle both $\mathrm{P}$ falciparum and $\mathrm{P}$ vivax infection. The non compliance issued can be solved by direct observed during taking the drug by village malaria volunteers. The result from study in Lampung and Purworedjo by Sutanto, et al. by using ACT plus primaquine as malaria treatment regimen, succeed in declining the problem of $P$. vivax $[11,22]$

Same situation found in Jembrana district. In 2008, the health services in Jembrana began to use ACT to all positive malaria cases, strengthened the early detection and diagnosis activity by training the microscopist as well as LLIN distribution. There is a significant decrease of malaria cases almost 20 times or $97,8 \%$ in 2009 . Lesson learnt from the increasing cases in the previous year, it was due to lacked and weakened of the surveillance activity where there were an imported cases who were lost to follow up and then infect local people and the silent transmission began until outbreak occurred. But since strengthening the program activities and set up the village malaria volunteers the next year the cases dropped sharply.

In the two study areas the comprehensive malaria control program which include the case finding, case detection, case confirmation and treatment were running well, either passively (PCD) or actively (ACD) which involving all health facilities from governmenrt as well as private and follow up treatment each of positive casse through direct observe by VMV. Other important prevention activities by using LLIN and environmental observation of larval breeding habitats also observed.

From the interviewed with stake holder, malaria programme manager and village malaria volunteers we got indepth information that to achieve malaria elimination need the high commitment as well as involvement from the Major and other related sectors, the commitment then followed by the availability of the funding for malaria control activities in continous way. The leadership of the head of district health office as important as the role of the chief Major. The comprehensive activities of malaria intervention from malaria promotion, prevention, early detection and prompt treatment, the transmission dinamic survey, rigorous surveillance activitty as well as the role of village malaria volunteers all are important and shoul be well in place and well funded.

\section{Limitations}

From this study with the retrospective data capture, we can not estimate the decreasing of malaria cases is due to using ACT treatment alone or because together by using LLIN for prevention. But due to complexity of malaria transmission no single effort can succed in controlling the malaria endemicity. From the study of Gamble CL,Ekwan and TerKuile et al in using the LLIN can reduced placental malaria in pregnancy women in Africa with relative risk as of 0.79 . From the study of W.A Hawley et al in Kenya using of LLIN at community level can reduce the risk of malaria morbidity and child mortality.

It is weakness generalizable these findings to other areas as a purposive sampling frame was used. However the strengths, challenges and experiences of the two study areas may provide other district malaria officer with insight in how to deal with similar challenges in their local context.

\section{Conclusion}

This study assessed the impact of new policy in malaria treatment using ACT in two areas Sabang city, in Aceh Province and Jembrana district in Bali province. Since 2008 as national malaria control program change its policy on treatment of malaria by using ACT plus primaquine, Sabang and Jembrana as the low endemic areas also implemented this new policy. The epidemiological data from Sabang showed a sharp decreasing of the of Annual Parasite Incidence (API) from 2008 to 2011 which is 3.7 to $0.08 / 1000$ population (reduced 46.25 times); no indigenous case found and good surveillance activity are in place especially migration surveillance conducted by village malaria volunteers. There was the activity of LLIN distribution with coverage of $100 \%$ of household. Similarly the malaria situation in Jembrana district, since used ACT for malaria treatment in 2008 and distributed LLIN for prevention, though only $8.6 \%$ coverage, resulted in decreasing of the API from 0.94 to $0.05 / 1000$ population in 2011 (reducing by 18.8 times), supported by good community surveillance and there is no more reported indigenous case. In these two areas already achieved three indicators for malaria elimination and can give the award or certification by $\mathrm{MoH}$ of Indonesia. Combining with the qualitative study we've got better information on what elements needed to achieve malaria elimination that are: high commitment from the leader, supported by adequate financial to run the good control program and continuously conduct capacity building to all health staff and active participation of community for conducting a community surveillance. Maintaining VMV as front-line workers appears to be necessary for keeping indigenous cases at or near zero.

\section{Competing Interest}

The authors declare that they have no competing interests.

\section{Authors' Contribution}

RK designed the study, coordinated the field work and wrote the manuscript, STB assited in study design and give inputs in aspects of entomology. IDP providing content analysis, methodology, topics of discusion and revised the manuscript. $\mathrm{HK}$ assisted in designing the study and guiding the whole process from data collecting, data analysis, report writing and revised the manuscript.

\section{Acknowledgement}

The authors are gratefull to all health staff in Sabang and Jembrana Health office as well as to Primary health staff, the surveillance officer, the microscopist, the vector control staff and to all malaria village volunteers. We thanks the survey team from the Ministry of Health Indonesia Mr Lukman Hakim, Mr Eddy Haryanto and Mr Budi Pramono, also to the Aceh and Bali provincial health staff. Highly appreciated to Profesor Dr. Peter Jay Hotes from Baylor college in giving the inputs for better writing of this paper.

\section{References}

1. World Health Organization (2007) Malaria elimination: Field manual for low and moderate endemic countries. WHO Guideline, Geneve.

2. Baird JK, Sustriayu Nalim MF, Basri H, Masbar S, Leksana B, et al. (1996) Survey of resistance to chloroquine by Plasmodium vivax in Indonesia. Trans R Soc Trop Med Hyg 90: 409-411.

3. Ministry of Health Indonesia (2008a) A National guideline Towards Indonesia Free from Malaria, Jakarta: Ditjen PPM \& PLP Depkes RI. 
Citation: $\quad$ Rita K, Satoto TB, Iwan D, Hari K (2014) The Use of Artesunate Combination Therapy (Acts) and Long- Lasting Insecticidal Net (LLIN) in Low Endemic Area to Achieve Malaria Elimination in Indonesia. Malar Chemoth Cont 3: 118. doi:10.4172/2090-2778.1000118

Page 7 of 7

4. Ministry of Health Indonesia (2008b) A guideline for case management of malaria in Indonesia edition of 2008, Jakarta: Ditjen PPM \& PLP Depkes RI.

5. Ministry of Health Indonesia (1993) A National guideline for malaria control program in Indonesia, Jakarta: Ditjen PPM \& PLP Depkes RI.

6. Subdirectorate of Malaria (2010) Annual report of malaria control programme in Indonesia 2010, Directorate of VBDC, Directorate General of CDC\& EH, Ministry of Health Indonesia.

7. Baird JK, Leksana B, Masbar S, Fryauff DJ, Sutanihardja MA, et al. (1997) Diagnosis of resistance to chloroquine by Plasmodium vivax: timing of recurrence and whole blood chloroquine levels. Am J Trop Med Hyg 56: 621-626.

8. Sutanto I, Suprijanto S, Nurhayati, Manoempil P, Baird JK (2009) Resistance to chloroquine by Plasmodium vivax at Alor in the Lesser Sundas Archipelago in eastern Indonesia. Am J Trop Med Hyg 81: 338-342.

9. Kusriastuti R (2011) Towards malaria elimination in Indonesia, Buletin Zoonosis, Directorate of Vector borne disease control. Ministry of Health Indonesia.

10. Kusriastuti R, Surya A (2012) New treatment policy of malaria as a part of malaria control program in Indonesia. Acta Med Indones 44: 265-269.

11. Sutanto I, Suprijanto S, Kosasih A, Dahlan MS, Syafruddin D, et al. (2013) The effect of Primaquine on Gametocite development and Clearance in the Treatment of Uncomplicated Falciparum Malaria with DiHydroartemisinin-Piperaquine in South Sumatra western Indonesia: An Open-label Randomized, Controlled Trial. Journal of Clinical Infectious Disease 56: 685-693.

12. Harijanto PN (2010) Malaria: Epidemiology Patogenesis, Clinical manifestation and its treatment. EGC medical book, Jakarta.
13. Price RN, Tjitra E, Guerra CA, Yeung S, White NJ, et al. (2007) Vivax malaria: neglected and not benign. Am J Trop Med Hyg 77: 79-87.

14. Sabang Health office, Aceh Province (2010) Annual report of Malaria control Porgram in Sabang 2010.. Dinas Kesehatan Kota Sabang.

15. Kusnanto H, Fuad A, Satoto TBT, et al. (2010) Malaria elimination Database Development in Sabang, Final Report, Sistim Managemen dan Informasi Kesehatan, Universitas Gajah Mada, Jogyakarta.

16. Elyazar IR, Sinka ME, Gething PW, Tarmidzi SN, Surya A, et al. (2013) The distribution and bionomics of anopheles malaria vector mosquitoes in Indonesia. Adv Parasitol 83: 173-266.

17. Tri Baskoro TS (2012) Molecular Marker Confirmation for Member of Anopheles Barbirostris Van Der wulp 1884 in Different Localities, Indonesian Journal of Biotechnology 17: 2.

18. Jembrana District Health Office (2011) Bali Province, Annual report of malaria program activities for 2008-2011.

19. Subdirectorate of Malaria (2013) Report of malaria control programme activity, World Malaria day in Indonesia, 25 April 2013, Directorate of VBDC, Directorate General of CDC\& EH, Ministry of Health Indonesia.

20. Ministry of Health Indonesia (2013): A revised guideline for case management of malaria in Indonesia edition of 2013,:Ditjen PPM \& PLP Depkes RI, Jakarta.

21. Herdiana H, Fuad A, Asih PB, Zubaedah S, Arisanti RR, et al. (2013) Progress towards malaria elimination in Sabang Municipality, Aceh, Indonesia. Malar J 12: 42.

22. Supargiyono S, Inge S, Dian N, A Kosasih, Willian AH, et al. (2013) Seasonal changes in the antibody responses against Plasmodium falciparum merozoite surface antigens in areas of differing malaria endemicity in Indonesia. Malaria Journal 12: 444. 